\title{
PstI FRAGMENT POLYMORPHISM IN THE GENE OF THE HUMAN ATP SYNTHASE BETA SUBUNIT
}

\author{
Kiyoshi Hasegawa, ${ }^{1}$ Shigeo Ohta, ${ }^{2}$ Kuniaki Narisawa, ${ }^{1}$ \\ Keiya TADA, ${ }^{1}$ and Yasuo KagAwA ${ }^{2}$ \\ ${ }^{1}$ Department of Pediatrics, Tohoku University School of Medicine, \\ 1-1 Seiryo-cho, Sendai 980 , Japan \\ ${ }^{2}$ Department of Biochemistry, Jichi Medical School, \\ Minamikawachi-cho, Tochigi 329-04, Japan
}

\begin{abstract}
Summary ATP synthase $\left(\mathrm{F}_{0} \mathrm{~F}_{1}\right)$ is a proton-translocating ATPase which is composed of two moieties, an intrinsic membrane sector $\left(F_{o}\right)$ and an extrinsic membrane sector $\left(F_{1}\right)$. ATP synthesis is catalyzed by the $F_{1}$ beta subunit. This paper reports restriction fragment length polymorphism (RFLP) of the human $F_{1}$ beta subunit gene identified with a cloned cDNA as a probe. Genomic DNAs from 27 unrelated Japanese individuals were analyzed by Southern blot hybridization. RFLP characterized by polymorphic bands at 3.2, 1.7, and 1.5 kilobase-pairs $(\mathrm{kbp})$ was detected in Pst I digests of the DNAs, and three genotypes were identified. Of the 27 persons, $16(59 \%)$ were homozygous for the $3.2 \mathrm{kbp}$ band and two $(8 \%)$ for both the 1.7 and $1.5 \mathrm{kbp}$ bands; the other nine persons $(33 \%)$ were heterozygous for these bands. Mendelian inheritance of the Pst I polymorphic bands was shown in 12 members in three generations of one family. The copy number of the $F_{1}$ beta subunit gene was determined as one.
\end{abstract}

\section{INTRODUCTION}

Proton translocating ATPase $\left(\mathrm{F}_{\mathrm{o}} \mathrm{F}_{1}\right)$ catalyzes ATP synthesis in oxidative phosphorylation and photophosphorylation (Cross, 1981; Kagawa, 1984). It is located in the mitochondrial inner membranes, chloroplast membranes and the plasma membranes of prokaryotic cells. The enzyme consists of two moieties: $F_{0}$, an intrinsic membrane sector; and $F_{1}$, an extrinsic membrane sector. ATP synthesis is catalyzed by the $F_{1}$ beta subunit using the energy of proton flux across these energytransducing membranes. The $F_{1}$ subunit structure is common to prokaryotic and eukaryotic cells. The genes have been cloned from prokaryotes such as Escherichia 
coli (Kanazawa and Futai, 1982; Walker et al., 1984) and thermophilic bacterium (Kagawa et al., 1986), and human cDNA for the beta subunit was recently cloned in this laboratory (Ohta and Kagawa, 1986). We report, here, the existence of restriction fragment length polymorphism (RFLP) of the human $F_{1}$ beta subunit gene identified with the cDNA as a probe. The Pst 1 polymorphism was found to be segregated in a Mendelian fashion in one family.

\section{MATERIALS AND METHODS}

Preparation of genomic DNA. Genomic DNAs from 27 healthy, unrelated Japanese individuals (24 males and three females) and from 12 members of one family (in three generations) were examined. The DNA was prepared from $10 \mathrm{ml}$ of heparinized blood by a modification of the method of Kunkel et al. (1977). By this procedure the yield of DNA was $100-300 \mu \mathrm{g}$.

Labeling of DNA. Probes were prepared by nick-translation (Maniatis et al., 1982) using the 1.8-kbp EcoRI fragment of full-length cDNA for the human $F_{1}$ beta subunit (Ohta and Kagawa, 1986). The specific activity of the ${ }^{32}$ P-labeled DNA was about $1.0 \times 10^{8} \mathrm{cpm} / \mu \mathrm{g}$. Lambda phage DNA digested with HindIII was used as a size standard. The $3^{\prime}$ ends of the digested DNA fragments were labeled with [22P]dCTP (deoxycytidine 5'-triphosphate) by Klenow DNA polymerase.

Gel electrophoresis and blot hybridization. Samples of $10 \mu \mathrm{g}$ of the purified DNA were digested with 100 units of various restriction endonucleases for $12 \mathrm{hr}$ according to the supplier's instructions, and the fragments were separated by electrophoresis in $0.5 \%$ or $0.8 \%$ agarose gels. DNAs denatured by treatment with alkali was transferred to a nylon membrane (Hybond N, Amersham) by the method of Southern (1975), and fixed on the membrane by ultraviolet irradiation for 5 min. The DNA blots were hybridized with the ${ }^{32} \mathrm{P}$-labeled probe $(10-50 \mathrm{ng} / \mathrm{ml}$ DNA) at $60^{\circ} \mathrm{C}$ for $20 \mathrm{hr}$ in $3 \times \mathrm{SSC}(0.45 \mathrm{M} \mathrm{NaCl}, 45 \mathrm{~mm}$ sodium citrate $), 10 \times$ Denhardt's solution (Maniatis et al , 1982), $10 \mathrm{~mm}$ EDTA (ethylenediamine tetraacetic acid), $0.5 \%$ SDS (sodium dodecyl sulfate), $0.1 \mathrm{mg} / \mathrm{ml}$ heat-denatured, salmon sperm DNA (Pharmacia) after prehybridization for 3-4 hr. The membranes were washed several times at room temperature in $2 \times \mathrm{SSC}, 0.1 \% \mathrm{SDS}$ and at $60^{\circ} \mathrm{C}$ in $2 \times \mathrm{SSC}, 0.1 \%$ SDS and $1 \times \mathrm{SSC}, 0.1 \% \mathrm{SDS}$, and then exposed to Kodak XAR-5 film at $-70^{\circ} \mathrm{C}$ with an intensifying screen for 1-3 days.

Determination of the copy number of the gene. The cloned genomic DNA for the human $\mathrm{F}_{1}$ beta subunit (submitted by Ohta et al.) digested with BamHI was mixed at various ratios with human placental DNA that had been digested with BamHI. Southern hybridization was done as described. The bands on autoradiogram were traced with a microdensitometer (Model FD-IV, Fuji Riken Co.) and the areas of the bands were measured to determine the copy number of the $F_{1}$ beta gene. 


\section{RESULTS}

\section{Detection of RFLP genotypes}

When digested with Pst I, the genomic DNAs of the individuals gave three electrophoretic patterns on hybridization (Fig. 1, Panel A). The first type showed bands at 3.2 and $2.9 \mathrm{kbp}$; the second showed bands at $3.2,2.9,1.7$ and $1.5 \mathrm{kbp}$, the $3.2 \mathrm{kbp}$ band being fainter than that at $2.9 \mathrm{kbp}$; and the third showed bands at $2.9,1.7$ and $1.5 \mathrm{kbp}$, but not at $3.2 \mathrm{kbp}$. The second type seemed to be a combination of the first and third ones, because 3.2 is the sum of 1.7 and 1.5 and the signal intensities of the two smaller bands increased while that of $3.2 \mathrm{kbp}$ band decreased. Thus the first and third genotypes were concluded to be homozygous (AA and BB, respectively), while the second one was heterozygous (AB) (Fig. 1, Panel B). Of 27
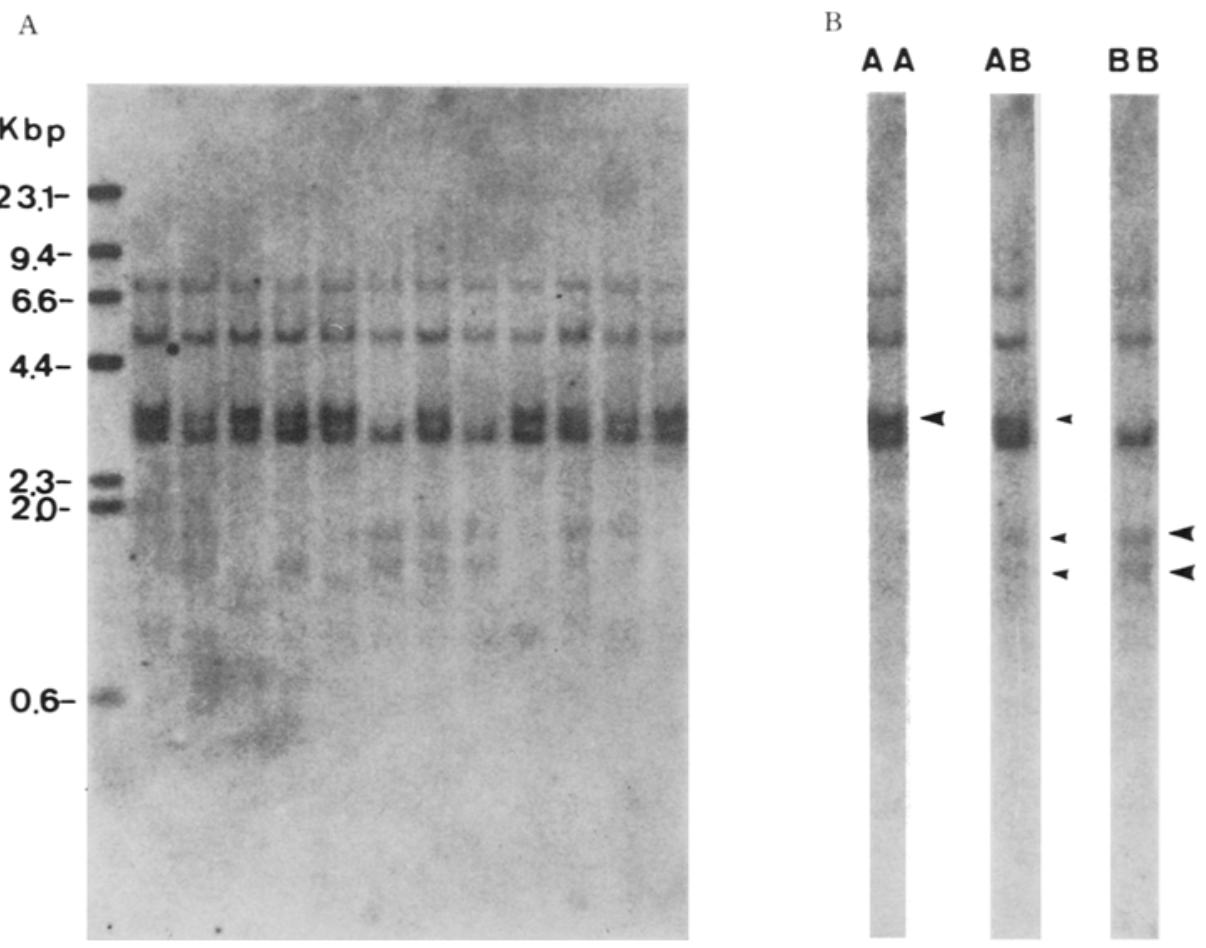

Fig. 1. (Panel A) RFLP detected with Pst I, Genomic DNA prepared from peripheral blood was digested with $P_{\text {st }} \mathrm{I}$ and hybridized with the ${ }^{32} \mathrm{P}$-labeled human $\mathrm{F}_{1}$ beta cDNA. Electrophoresis was performed in $0.8 \%$ gel. The left lane shows the positions of end-labeled lambda DNA fragments digested with HindIII as markers. (Panel B) Three genotypes, AA, AB, and BB, identified by the patterns of three polymorphic bands at $3.2,1.7$, and $1.5 \mathrm{kbp}$ are shown. The three polymorphic bands are indicated by arrows. 
unrelated Japanese individuals, $16(59 \%)$ had the genotype AA, nine $(33 \%)$ had the genotype $\mathrm{AB}$, and the other two $(8 \%)$ had the genotype $\mathrm{BB}$. The observed genotype frequencies did not differ from those expected based on Hardy-Weinberg equilibrium.

No difference in other bands in the PstI digests was detected. Furthermore, no other RFLPs have so far been found with the restriction enzymes BamHI, Eco RI, HindIII, KpnI, and SmaI (See Fig. 2 for examples).

\section{Inheritance of genotypes}

Three genotypes were identified by the Pst I polymorphism as shown in Fig. 1, Panel B. To confirm that these genotypes show Mendelian segregation, we examined the genotypes of 12 members in three generations of one family. The results in Fig. 3 show that this polymorphism was segregated in a Mendelian fashion.

\section{Copy number of the $F_{1}$ beta gene}

The copy number of the human genomic $F_{1}$ beta subunit gene was determined to find out whether the polymorphism appeared in a bona fide gene. For this, autoradiograms obtained by hybridization of the mixture of placental DNA and cloned human genomic DNA were analyzed quantitatively. At the concentrations of material used for Fig. 4, the areas of bands were linearly related to the concen-

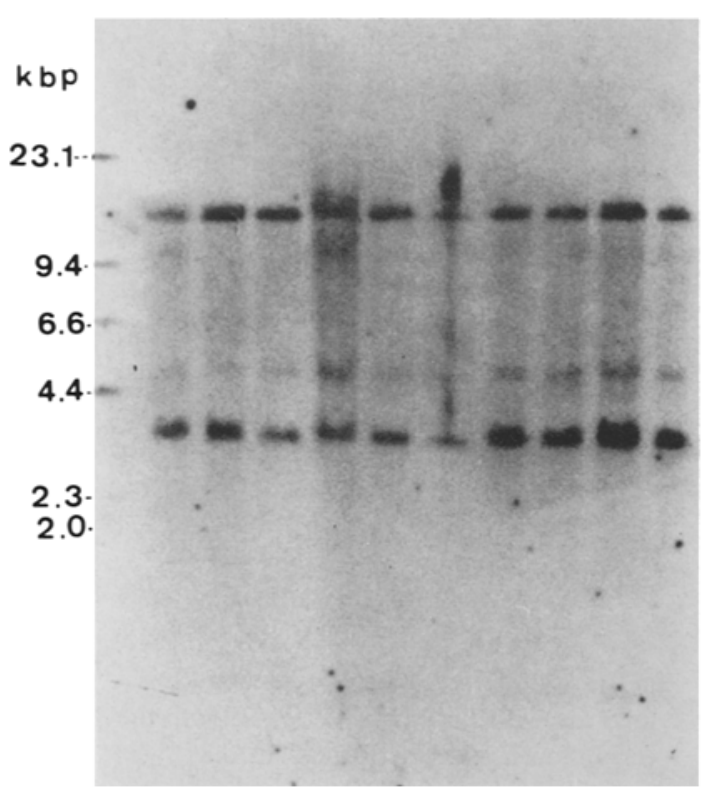

Fig. 2. Autoradiogram of digests with HindIII. No polymorphic bands are seen. The left lane shows the lambda DNA fragments described in Fig. 1. Electrophoresis was performed in $0.5 \%$ agarose gel. 


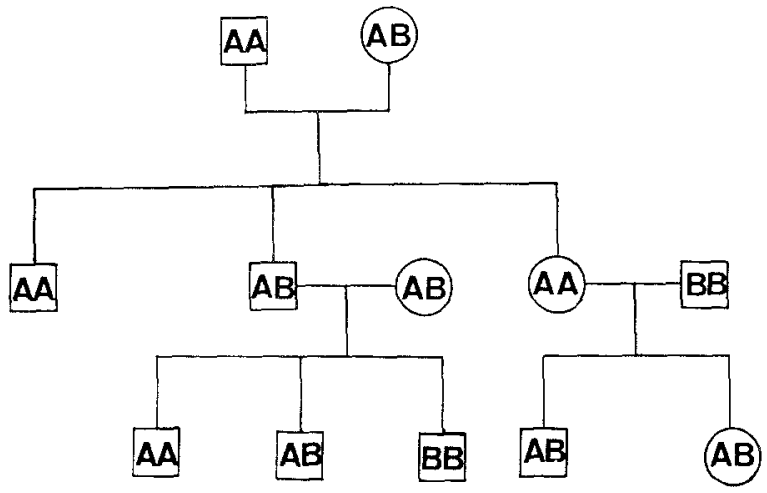

Fig. 3. Inheritances of the genotypes. The genotypes of 12 individuals in three generations are shown. $\mathrm{AA}, \mathrm{AB}$, and $\mathrm{BB}$ are the genotypes described in Fig. 1.

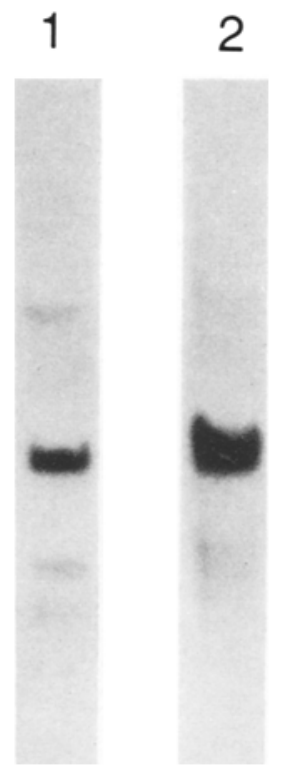

Fig. 4. Determination of the copy number of the human $F_{1}$ beta subunit gene. Ten $\mu \mathrm{g}$ of human genomic DNA (lane 1) and a mixture of $10 \mu \mathrm{g}$ of the DNA and an equimolar of the cloned genomic $F_{1}$ beta gene (lane 2) were digested with BamHI and subjected to $0.5 \%$ agarose gel electrophoresis followed by Southern blot hybridization.

trations (data not shown). In Fig. 4, the ratio of the areas of the bands in lanes 2 and 1 was 1.9. Therefore, it was concluded that the copy number of the $F_{1}$ beta gene in the human genome was one, and that the polymorphism was located on a functional gene. 


\section{DISCUSSION}

The subunits of the catalytic portion of ATP synthase in human mitochondria are encoded on a nuclear genome, synthesized in the cytosol as larger precursors and then assembled inside mitochondria with the subunits encoded on a mitochondrial genome (Hay et al., 1984; Ohta and Schatz, 1984). Studies on the synthesis of $F_{1}$-ATPase are of wide biological interest in many respects such as the expression of gene products under various external conditions, the interaction between mitochondrial and nuclear genomes, and the evolution of nucleotide binding proteins. The cDNA of the human $F_{1}$ beta subunit has been cloned (Ohta and Kagawa, 1986). Furthermore, the genomic gene has recently been cloned (Ohta et al., subumitted). By these clonings, we can now investigate the above problems, and the gene can be used as a genomic marker.

In this work, we detected the existence of Pst $\mathrm{I}$ fragment polymorphism in Japanese individuals. The frequencies of three genotypes, $\mathrm{AA}, \mathrm{AB}$, and $\mathrm{BB}$, classified on the basis of the patterns of the polymorphic bands were 59,33 , and $8 \%$, respectively. The polymorphism seemed to be due to the presence or absence of an additional Pst I site in the genomic $3.2 \mathrm{kbp}$ Pst I fragment. Judging from the structure of the cloned gene, this additional site is located in the third intron as shown in Fig. 5. The bands obtained in digests with various other restriction enzymes were consistent with the normal gene structure. We found that the copy number was one per haploid. The Mendelian inheritance of this RFLP was demonstrated by analysis of the segregation pattern in one family. These data are useful for human gene mapping. Chromosomal assignment of the gene is now on the way.

Mitochondrial myopathies are heterogeneous disorders that can affect multiple organs including skeletal muscles. DiMauro et al. (1985) classified it into three types: defects of substrate utilization; defects of oxidation and phosphorylation coupling; and defects of the respiratory chain. The biochemical bases of mitochondrial myopathies are, however, not fully understood. A case of mytochondrial

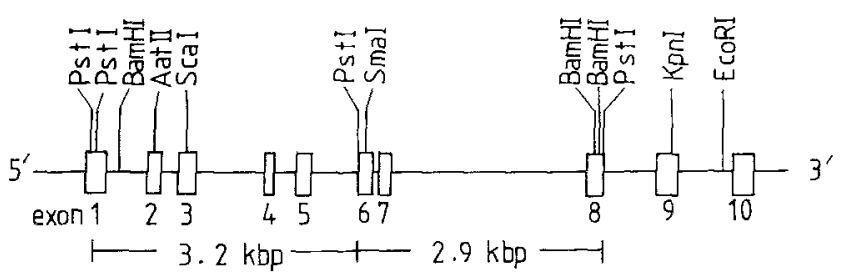

Fig. 5. Structure of the genomic gene of the human $F_{1}$ beta subunit. Ten exons and some restriction sites are shown (Ohta et al., submitted). Note that the two $P_{s t} \mathrm{I}$ fragments of 3.2 and $2.9 \mathrm{kbp}$ correspond to the fragments of genotype AA in Fig. 1, and that the BamHI fragment corresponds to the fragment used for determination of the copy number in Fig. 4. 
myopathy that had the defect in ATPase activity was reported by Schotland et al. (1976). Data on RFLPs and molecular studies of ATP synthase may be helpful for diagnosis or understanding of the mechanisms of mitochondrial diseases, as they are the other neuromuscular disorders (Gusella et al., 1984; Murray et al., 1982).

Acknowledgments We thank Dr. S. Miyabayashi of Tohoku University for valuable discussions on mitochondrial myopathies. We also thank Dr. K. Kawakami of Jichi Medical School, Department of Biology, for a gift of purified placental DNA, and Misses K. Matsuda and M. Hoshino for their excellent technical and secretarial assistance. This work was supported in part by a Grantin-Aid for Scientific Research (\#604432) from the Ministry of Education, Science and Culture of Japan.

\section{REFERENCES}

Cross, R.L. 1981. The mechanism and regulation of ATP synthesis by $\mathrm{F}_{1}$-ATPases. Annu. Rev. Biochem. 50: 681-714.

DiMauro, S., Bonilla, E., Zeviani, M., Nakagawa, M., and DeVivo, D.C. 1985. Mitochondrial myopathies. Ann. Neurol. 17: 521-538.

Gusella, J.F., Tanzi, R.E., Anderson, M.A., Hobbs, W., Gibbsons, K., Raschtchian, R., Gilliam, T.C., Wallace, M.R., Wexler, N.S., and Conneally, P.M. 1984. DNA makers for nervous system diseases. Science 225: 1320-1326.

Hay, R., Boehni, P., and Gasser, S. 1984. How mitochondria import proteins. Biochim. Biophys. Acta 779: 65-87.

Kagawa, Y. 1984. Proton motive ATP synthesis. In Bioenergetics, Ernster, L., ed. Elsevier Scientific Publishing Co., Amsterdam, pp. 149-186.

Kagawa, Y., Ishizuka, M., Saishu, T., and Nakao, S. 1986. Stable structure of thermophilic proton ATPase beta subunit. J. Biochem. 100: 923-934.

Kanazawa, H. and Futai, M. 1982. Structure and function of $\mathbf{H}^{+}-$ATPase: what we have learned from Escherichia coli $\mathrm{H}^{+}$-ATPase. Ann. N.Y. Acad. Sci. 402: 45-64.

Kunkel, L.M., Smith, K.D., Boyer, S.H., Borgaonkar, D.S., Wachtel, S.S., Miller, O.J., Breg, W.R., Jones, H.W., Jr., and Rary, J.M. 1977. Analysis of human Y-chromosome-specific reiterated DNA in chromosome variants. Proc. Natl. Acad. Sci. USA 74: 1245-1249.

Maniatis, T., Fritsch, E.F. and Sambrook, J. 1982. Molecular Cloning, Cold Spring Harbor Laboratory Publication, New York, pp. 109-112.

Murray, J.M., Davies, K.E., Harper, P.S., Meredith, L., Mueller, C.R., and Williamson, R. 1982. Linkage relationship of a cloned DNA sequence on the short arm of the $X$ chromosome to Duchenne muscular dystrophy. Nature 300: 69-71.

Ohta, S. and Kagawa, Y. 1986. Human F-ATPase: molecular cloning of cDNA for the beta subunit. J. Biochem. 99 : 135-141.

Ohta, S. and Schatz, G. 1984. A purified precursor polypeptide requires a cytosolic protein fraction for import into mitochondria. EMBO J. 3: 651-657.

Schotland, D.L., DiMauro, S., Bonilla, E., Scarpa, A., and Lee, C..P. 1976. Neuromuscular disorder associated with a defect in mitochondrial energy supply. Arch. Neurol. 33: 475-479.

Southern, E.M. 1975. Detection of specific sequences among DNA fragments separated by gel electrophoresis. J. Mol. Bisl. 98: 503-517.

Walker, J.E., Saraste, M., and Gay, N.J. 1984. The unc operon, nucleotide sequence, regulation and structure of ATP-synthase. Biochim. Biophys. Acta 768: 164-200. 